\title{
A critical exploration of 'access' in qualitative International Business field
}

research: towards a concept of socio-cultural and multidimensional research

\author{
practice
}

\begin{abstract}
Purpose:

Researchers often face challenges in locating and obtaining relevant and meaningful information during qualitative International Business (IB) field research in other countries. This process constitutes an immensely critical phase, which determines the success or failure of the research endeavour. This article discusses 'access' as a multidimensional and contestable concept, that poses particular challenges in international and multicultural research contexts.

\section{Design/methodology/approach}

This article builds on our experience as field researchers in China/Hong Kong (120 in-depth interviews) and the need to disseminate acquired field experiences, in particular concerning 'access'. The multifaceted issue of 'access' is rarely featured on the IB methodological agenda, and has become a silent feature of qualitative IB research.
\end{abstract}

\section{Findings}

This article is devoted to this nexus: the lack of focus on 'access' issues, and the rich sources of acquired, but mostly veiled, field experiences that feature in both international business and management research programmes. A plausible explanation for this circumstance relates to the influence of mainstream positivist and objectivist paradigms in which researchers are not recognised as having an impact on research processes, hence taking this silent feature for granted.

\section{Originality/value}

By viewing the multiple dimensions of 'access', we move beyond the mainstream understanding that merely relates it to the question of gaining access to a physical site and/or the time of an individual, and in which 'access' is only an enterprise of securing pre-existing, tangible information. Drawing upon specific international fieldresearch experiences, this article contributes to the methodological debate concerning 'access' - beyond 'technicality' and towards a concept of socio-cultural and multidimensional research practice.

Keywords: 'Access', qualitative research, fieldwork, International Business and Management research, field researcher, international field research experiences, multidimensional; critical exploration.

\footnotetext{
The authors would like to thank the two anonymous reviewers and the Guest Editor, Prof Karen Locke, for the very helpful and insightful recommendations. The authors are also very grateful to the David C. Lam Institute for East-West Studies (Hong Kong Baptist University) for bestowing upon both researchers a Resident Graduate Scholarship towards conducting field research in China/Hong Kong.
} 


\section{Introduction}

'Access' to organisations, institutions, and individuals is fundamental to qualitative research and ultimately determines the success or failure of the research (Alcadipani and Cunliffe, 2014). It is a crucial element which is beyond the full control of the researcher. In this article, we examine the challenges that may arise during qualitative international field research. Our inquiry moves beyond merely acknowledging the issue of obtaining physical access to organisations and research subjects to acknowledge the various dimensions of 'access' and the role of sociocultural factors, which may impinge on the ability to gain 'access'. Interrogating the socio-cultural dimension concerning 'access' is particularly imperative in international research settings. This is because the researcher must be able to access the relayed context-specific meaning-construction by respondents' utterances, in addition to tackling potential cultural impediments regarding the processes of gaining access to relevant individuals, their time, and organisations. This is further complicated amongst interviewees from unfamiliar cultural backgrounds, within organisations and institutions that are embedded in diverse socio-historical traditions (Guttormsen, 2015; Holmes, 2015).

Our analysis refers to our international fieldwork projects and the lessons learned in relation to seeking 'access' to organisations such as Multinational Enterprises (MNEs) and to individuals in non-work communities. In International Business (IB) and Management methodology textbooks, and in research in general, the focus on 'access' as a multidimensional social phenomenon remains diminutive. Previous research tends only to make a brief reference to accessing physical space (a territorial understanding of the term), for example, a work-site which researchers 
cannot assume having an open access to. We are drawing upon our experiences of conducting field research in China through which we learned to approach 'access' as a continuous process that needs to be unpacked in order to be holistically appreciated.

'Access' is a highly personal activity that is related to experiences encountered in the field (Feldman et al., 2002) as well as politics, for example, in reference to, social issues and moral dilemmas faced by researchers and encountered organisations (Alcadipani and Cunliffe, 2014). Factors such as emotions, culture and intersubjectivity, as well as social and language skills, can substantially influence the success or failure to secure 'access'. The entanglement of the researcher (as a social being) in the actual 'access'-seeking process is an important aspect to consider, due to the vast array of ways in which this involvement may influence the outcome of the research project. A plausible explanation for why the role of field researchers is seldom addressed is that researchers are often located outside the ontological focus in the mainstream, positivist-rooted quantitative IB research.

The findings of this article reveal that 'access' can be understood as a social phenomenon, in addition to being a multi-dimensional, contestable conceptual term. Contributions relating to the notion of 'access' itself can thus be de-constructed to mean many more things than the mere issue of sourcing 'physical' access to information or research subjects, which are tacitly assumed to represent uncontaminated data, free from the influence of context or the relationship between the researcher and the researched (see Brewer, 2000). We share Alcadipani and 
Hodgson's (2009) perspective that there is a strong need to move beyond notions of 'access' merely as an operational undertaking.

Beyond the above-mentioned academic disciplinary concerns, scrutinising the methodological issues of 'access' in the specific context of international business is warranted on a number of counts. First, the innately international nature of international business organisations and those working within them means that they are constantly grappling with intercultural challenges. In such circumstances, the environment is more multifaceted and complex and, thus, there are more obstacles to gaining 'access' than might be the case during encounters with domestic firms and organisations. Second, unlike many public, intergovernmental, civil society, and nongovernmental organisations (NGOs), or communities in the public sphere, private sector organisations tend not to have a culture, or widespread organisational activities, which relate to non-commercial research and/or public engagement and outreach. Consequently, the second author found that accessing international business practitioners poses a bigger hurdle than, for example, securing interviews with those working in organisations where engagement with broader society forms part of the employee's job description and the identity of their employers.

This article continuously combines and intertwines empirical lessons with theory through presenting the analysis of two distinct stories from international fieldwork. The first author investigates individual level perceptions of headquarters-subsidiary knowledge transfer processes in Swedish MNEs. The case-study methodology deployed included field research in China for a total duration of six months. The second author conducted a five-month ethnographic field study of Scandinavian 
expatriates in Hong Kong SAR, exploring perceptions of intercultural encounters, expatriate failure and adjustment experiences, also focussing on the level of the individual. The article is structured as followed: the literature review is followed by a discussion of lessons learned in the field; we then present a framework which consists of our proposed multiple dimensions of access, namely personal, administrative, physical, and socio-cultural; the final section presents a discussion of our findings and the conclusion.

\section{Literature review}

Despite being a multifaceted and complex issue which is strongly influenced by an array of intersubjective and personalised aspects, the critical issue of 'access' during qualitative field research needs to be explored and scrutinised in much more depth within the IB research agenda. We find that mainstream methodological literature has often limited its treatment of 'access' by regarding it as a one-dimensional act of securing physical access to interviewees. Furthermore, there is little focus on actual research practices (Cole, 2013). Feldman and colleagues (2002) explain that access is a dynamic rather than static learning process, where researchers need to understand their relationship with their surroundings. The IB literature is evidently rooted in a positivist research paradigm, which permeates most areas of the IB research agenda (Bate, 1997; Buckley and Chapman, 1996a; 1996b; Casson, 1996; Chapman, 1997; Guttormsen, 2015; Lauring and Guttormsen, 2010; Primecz et al., 2011). In this tradition, 'proper' science manifests objectivity, meaning it is inevitable that our role as researchers will be neglected as we are assumed to be detached from both the research process and our research subjects. Such an underlying ontological premise arguably leads to the neglect of crucial issues such as the 
personal and socio-cultural aspects of gaining 'access' during IB field research, despite playing an intricate part of the research process, as an 'instrument' of the study (Sanday, 1979).

The 'dialogical methodological' approach deployed in this article endeavours to broaden the IB methodological agenda through engaging with some of the important discoveries which have made in the broader social science disciplines. These include having an increased focus on the researcher's personal experiences and learning (Magolda, 2000; Olesen, 1994; Rabinow, 1977; Whyte, 1997), in addition to giving a voice to the actual methodological practices in the field (Van Maanen, 1988) - in particularly within an international context. Moreover, in terms of voice, Locke and Velamuri (2009) address concerns relating to the research subjects themselves, through granting them access to view ongoing draft versions of manuscripts. An additional point regarding 'access to information' relates to conducting qualitative research in order to enhance understanding of the collected quantitative data, for example as part of a mixed-method study (Locke, 2011a).

'Access' can also be thought of as an epistemological and methodological issue that concerns researchers, for example, in their pursuit of achieving 'methodological fit' (Edmondson and McManus, 2007). Consequently, the type and nature of 'access' sought by a researcher must be consistent with other internal elements in the research design. However, 'access' is also an external factor, the lack of which may hamper the feasibility of the research project itself. The eminent scholar and father of cross-cultural management research, Geert Hofstede, postulated in an interview (Carraher, 2003, p. 103): 
I mean, if you have an Uncle who is the director of a race course in Hong Kong, you may decide to do a study of race courses. Because by this specific fact, you have access to data nobody else has. So, do this and look at your assets and liabilities.

There are notable exceptions to the relative silence on the topic of 'access' in IB research in the Handbook of Qualitative Research Methods for International Business (eds Marschan-Piekkari and Welch, 2004). For example, Macdonald and Hellgren (2004) highlight that the organisational and informational hierarchies within firms cannot be assumed to be identical; senior managers may not always possess the most relevant knowledge on a particular topic. Furthermore, Chapman, Gajewska-De Mattos and Antoniou (2004) showcase several issues relating to field researchers' personal backgrounds and how these inescapably influence intersubjectivity and interpersonal interactions in the field. Moreover, in a recent conference paper relating to access, Peticca-Harris, deGama and Elias (2014) illustrate how awkward and uncomfortable personal situations had an impact on the research process, leading to the practice of questioning their own tacit assumptions.

Methodological deliberation regarding 'access' has received much deeper engagement in the broader social sciences beyond Business and Management Studies. Sociologist Robert Jackall (1988) elaborates extensively on the interpersonal experiences involved in gaining access to American corporate organisations in his interpretive sociological account which scrutinised the perceptions of managers relating to how they thought the world works, examining the shaping of moral consciousness. 'Access' runs through the work of Spradley (1979) as an underlying theme concerning the conduct of ethnographic research, but the 
principle focus is on locating research subjects rather than linking socio-cultural aspects to the social phenomenon of 'access'.

Thus, we argue that greater attention should be paid to the issue of 'access' in IB and research methodology due to it being not only relevant but necessary. This call is even more pertinent for international field-research endeavours due to the increased challenges that are faced when operating in unfamiliar cultural terrains. Students, academics, consultancy practitioners and managers alike might draw upon the experiences of other field researchers, both as authors of academic projects and as consultant researchers in international organisations in the private and publicsphere. As part of a learning process, this additional perspective may prove useful in the design and conduct of future research projects.

\section{In the field: lessons learned when seeking 'access'}

In this article, we question and discuss 'access', drawing upon our own field research experiences; how did we develop, experience, and tackle challenges in terms of gaining appropriate 'access' during our fieldwork in China? We will be presenting our field research experiences as two parallel field stories, which are based on our research engagements, which collectively comprised of 120 interviewees in China. These in-depth interviews exposed us to diverse challenges in terms of seeking and securing 'access', including narratives of lived experiences in China through relevant research subjects and locations.

We term the discussion framework (i.e. transferring field research experiences) we employ a 'dialogical' methodological approach. First, we identify commonalities 
between ourselves as field researchers to enable readers to evaluate our analysis through juxtapositioning, i.e. Chinese cultural context; as researchers, we share a Scandinavian socio-cultural and linguistic background; and conducting qualitative field research. Second, we agreed that the collaboration might contribute significantly to two main areas which are learning and the materialisation of knowledge. For example, juxtaposing our field experiences may enhance not only general methodological knowledge concerning field research practices but may also result in increased transparency and an improvement in the self-reflexive questioning of own practices. This undertaking provided us with a much deeper understanding of our own acquired experiences and an awareness of the relevant challenges in an international context, which had previously laid dormant in our minds and which concerned 'access' issues as lived experiences during our field research endeavours.

In practical terms, as authors, we both produced lengthy documents about our personal field experiences in China with regard to 'access' and we exchanged notes, subsequently commenting on each other's experiences and reflecting on our own initial statements. This approach served as the foundation for identifying the different dimensions of 'access' emerging from the analysis of our diaries (see Radcliffe, 2013, for an example of this approach). The dimensions constituted worthwhile themes to address as well as an encouragement to qualitative researchers to assess - and reassess - personal fieldwork experiences as 'discovery-activities' (Locke, 2011b; see Mikkelsen, 2013) by unveiling important methodological contributions. It was also seen as helpful for enlightening researchers about their investigation as participants themselves (Bryman, 2008; Orr and Bennett, 2009), and for making the 
invisible visible (Donnelly et al., 2013). Keeping diaries is a means of acquiring, structuring, and analysing not only research insights but also contextual reflections regarding the research questions and objectives of the study, the processes of gaining 'access' and the factors impinging on the depth and scope of information relayed to them by interviewees and gatekeeping organisations. Outsiders are able to reassess each other's reflections, which enabled us to reduce the risk of reflexive narcissism, as pointed out by Tomkins and Eatough (2010).

This article reflects the outcome of such a 'dialogical' process. The case-studies illustrate field-research experiences that relate to how the multifaceted issue of 'access', can be captured and categorised into various dimensions, albeit not in a taxonomical sense as they are in constant interplay with context-specific factors and are thus always interdependent.

\section{Interpersonal dimension}

Because field researchers are integral, to various extents, in the research process (Sanday, 1979), our personal capabilities and backgrounds as field researchers became an extremely important factor upon which to reflect. Qualitative researchers cannot be guided solely by what positivists affectionately refer to as 'theoretical gaps' when delineating the research problem of a new project. Although the former group of researchers are also guided by research questions at some level (Wolcott, 1995), qualitative researchers, however, must also take into account their own personas and personal abilities. This is because the personal background, intellectual position, and interpersonal relationships with research subjects might have a bearing not only on how 'access' might be secured but also the nature of data-collection and the 
analysis (Spradley, 1979). A quantitative researcher investigating, let us say, Malaysian Outward Foreign Direct Investment by analysing secondary data (for example, Goh et al., 2013) is likely to face fewer interpersonal issues. Such issues may, however, also transpire for quantitative researchers whilst in the field, in terms of negotiating to physically access relevant data and obtaining the permission to use this data (see Buckley, 2004). This becomes increasingly important when conducting qualitative and ethnographic research due to the close social interaction with and observation of research subjects, and the demanding requirements needed to acquire a comprehensive meaning and context-based understanding as a 'native'. Consequently, as with the example depicted above, 'access' constitutes merely a technical factor.

The interpersonal dimension is related to 'access' in the physical dimension (see Figure 1). It relates to how, to what extent, and for how long we have access to the physical dimension, as they are interconnected. Identifying the right contact person is only one crucial step along the way. As researchers we must decide to share our research ideas, interact, build relationships and establish trust in order to establish access to the subject (organisation or person) we want to study. Thus, the interpersonal dimension is important regardless of whether or not one achieves 'physical' access. The overall process of 'access' is an on-going, intersubjective and $\begin{array}{llll}\text { interpersonal } & \text { encounter } & \text { (see } & \text { Spradley, }\end{array}$

Most of the personalised factors were being played out beyond our control as the field researchers. This was a result of intersubjectivity and the fact that respondents interpreted the persona and background of the researcher in different ways. We 
would carefully plan how to dress when interacting with research subjects. In the first case, the interview sessions were gauged to constitute a very formal situation, which demanded formal attire. The researcher was invited to formal business lunches and dinners, as well as other professional and corporate events. This enabled her to network effectively and, subsequently, to meet potential interviewees. She would also emphasise the importance of building a network with contact persons and interviewees in MNEs after establishing trust. They may then choose to assist with introductions to people of interest in terms of the research, within the organisation and beyond. Understanding the dress-code (in terms of local culture and expectations/traditions within the given organisation) should not be underestimated especially when conducting research in another country where such practices might not be obvious to the researcher.

Building trust after establishing contact also became necessary as these 'gatekeepers' have the authority to grant 'access' to their company. They do not get paid for facilitating, and often lack the time to interact with researchers. Thus, we both found that part of our persona and skills, as researchers, was convincing the individuals concerned about what exactly the firm might gain from partaking in the research, and this became a key factor in our success. For example, a researcher may be willing to spend time in the organisation at no additional cost whilst carrying out research of some kind with the prospect of presenting findings and proposing managerial implications for the firm. This type of consultancy work is often of interest to firms if they deem the research topic interesting. This highlights that the contestable term 'access' is also a two-way, albeit asymmetric (in terms of powerbalance), continuous process. 
In the second case-study, the male researcher dressed 'smart casual' in order to avoid being too informally dressed for an office environment but not too overdressed for a meeting at a cafe. This enabled him to easily move between various interview sites and also to be prepared for sudden changes of locality or being invited out for a meal or drink in a professional environment. This was especially helpful when interacting with expatriates from non-corporate sectors. Stereotypically, for example, being dressed as a "financial investor" in a remote suburb of Hong Kong may cause interviewees to feel less inclined to divulge all their personal thoughts about corporate expatriates as the Other. This helped to elicit nuanced, but important, commentaries from interviewees. For example, a Swedish NGO expatriate working in Hong Kong commented the following, as a means to express the different categories of expatriates:

"I am not exactly with your "average company" (...) it might be interesting for you to learn about a different type of "expat" life".

As signalled above, the different types of expatriates can be context-specific to the area/country. Hence, gaining 'access' to such understanding demonstrates the importance for researchers to be informed by these nuances, as they tend to vary between cultural and national boundaries. Furthermore, he gained an advantage by employing his skills as an organist, which positioned him to meet new people, experience the Scandinavian community from the inside and, on a more personal level, make friends within the Scandinavian church community and beyond, which benefited both his research and his social life beyond the work realm. 


\section{Administrative dimension}

Whilst carrying out fieldwork, researchers are not only conducting research but are also solely responsible for all the administrative and managerial tasks that come to the fore then they find themselves removed from their offices and colleagues. Furthermore, they need to quickly adapt to an unfamiliar cultural environment. With research endeavours increasingly taking place in newer and potentially less familiar emerging markets, adjustment challenges only heighten in intensity (Guttormsen, 2015). Such a scenario poses additional challenges because of the pressure to complete the de rigueur research within a limited timeframe and budget.

The significant amounts of time that need to be allocated to the administrative side of the endeavour are seldom highlighted in methodological textbooks. For example, in the first case, coordinating interviews across ten subsidiaries located in different cities and provinces in China proved to be a challenge. This required the organisation of a complex itinerary featuring multiple flights, trains, and accommodation locations but with very little room for flexibility after the schedule had been finalised. Sometimes interviews were postponed for days, or even weeks. It is vital to be aware that the targeted professionals frequently operate within tight time schedules, particularly those employed by MNEs. Depending on the size and scope required for the particular project, it is advisable to estimate around 3-9 months for establishing and securing access, in addition to factoring in additional time in case of changes, in order to ensure that a sufficient number of interviews are obtained. Postinterview, it is important to acknowledge the interviewee's contributions and interest in the research, for example by sending a postcard. 
Similarly, in the second case, it can be reported that almost one working day per week was spent on administrative tasks ranging from contacting people, maintaining contacts whilst approaching new ones, keeping a diary of interview appointments with contact details, planning where and when to meet, distributing interview material to respondents, and recording background details, in a continuous loop. Indeed, this work onus drew attention away from the core research, and it should be carefully considered by researchers when planning their fieldwork endeavours. Thus, when evaluating field research practices and learning from them, it is also necessary to take into account the all-important supporting mechanisms that enable the actual processes of gaining 'access'. Across both cases, a key lesson also relates to the importance of logistical planning, and to do so by also factoring in the requirements, contexts, and obstacles which are applicable in a particular country: for example, means of transport and the locations of different companies.

\section{Physical dimension}

The physical dimension of 'access' is what is normally discussed in the mainstream literature, i.e. a physical boundary such as a firm's building or a particular enclosed expatriate community (Lauring, 2007) which field researchers must seek permission to cross. Taylor and Land (2014) point out that such access needs to be negotiated at the very early stages of seeking access and collecting data. This was, indeed, the everyday reality in the first case, experienced through personal networks or cold calling. Emails, letters, and telephone calls, or a combination of them, were used extensively. Researchers need to identify who to target inside the MNE; this may refer to position, gender and cultural background, as well as knowledge and skills. The initial person serves as a gatekeeper and decides what to action and who to 
forward to - or not. When the identity of the best person to speak to was unknown, the author often found herself being randomly forwarded by the initial person in the hope of identifying the appropriate person.

Due to the uncertainty associated with this process, researchers must seek all possible ways of securing 'access'. The first researcher used up to twelve different ways of attempting to secure access to an MNE including contacting the Swedish headquarters and different affiliated subsidiaries in China, attempting to identify employees working there, sending emails to different addresses, and making telephone calls. Sometimes she found that one person would accept her request for 'access', but another individual within the same organisation would turn her down at a later stage. Thus, locating the person with the appropriate authority to make this decision is crucial. The paradox of access (Feldman et al., 2002) posits that we have more to gain than to give in regard to 'access'. In order to increase the attractiveness of the research project we need to emphasise the benefits of the study. The benefit to the company should be explicit and emphasised. Moreover, introduction letters should be kept as short as possible, considering the busy schedules of those receiving them. Such activities are not part of their normal workload, and researchers must therefore succeed immediately in attracting their interest. It is important to avoid confusing employees with cumbersome academic language. A polite, formal, and professionally written letter is preferred. What is deemed culturally appropriate and sensitive in this regard can vary substantially between different cultures, countries, and industries. Thus, a standard approach regardless of the location of the fieldwork is not advisable. 
For the researcher in the second case, issues relating to physical access to firms were experienced to a much lower degree. His research focused predominantly on expatriates as individuals and members of a perceived Scandinavian "expatcommunity" rather than being constrained to a physical area or processes within firms. This made it easier to approach individuals directly at social events outside the physical premises of organisations and to act on informal introductions to potential interviewees. This did not mean, however, that firms were not part of the research. For example, when interviewees discussed intercultural issues, experiences at work were commonly raised, and it was natural context to talk about. Moreover, the individual and organisational levels cannot be taxonomically demarcated. He also approached firms by using 'snowball' and 'reflexive' sampling approaches (see Guttormsen, 2010; 2009), but did so in an attempt to locate individuals in their capacity as expatriates rather than as representatives of the firm. This recommendation might solicit a higher number of respondents, i.e. where 'access' practices are reformulated from organisations to individuals. Participation was also elicited by 'advertising' the study in Scandinavian publications and through relevant organisations in Hong Kong (Guttormsen, 2010).

'Access' to research subjects, as well as the lived experiences that we wanted to investigate, is thus also a result of flexibility on the part of the researcher and their ability to work around interviewees' commitments. The second researcher found this approach successful: he set up in-depth interviews in circumstances most convenient to the respondents, regardless of location (which ranged from an office to a participant's home) and time (during or outside office hours, including weekends). In Hong Kong, work hours often continue to 9pm (in addition to Saturdays). Hence, a 
tenacious 'Scandinavian 7.30am-3pm' work attitude would have been a disadvantage. This also challenged his psychological stamina and his ability to concentrate, for example, sometimes interviews might be conducted at 9am, $12 \mathrm{noon}, 4 \mathrm{pm}$, and then $8 \mathrm{pm}$, take place in several languages (i.e. Danish, English, Norwegian, and Swedish) and involve travelling across the Territory. The scope of 'access' is a fluid dimension that depends on the context, research question and purpose.

There is no 'correct' number for an 'appropriate amount of interviewees' as far as a qualitative piece of work is concerned. It depends on the research context and the study's research question and objectives. Qualitative researchers need to consider that the various components of 'access', including relationships, trust, and conducting the interviews themselves, take time to develop and maintain in practice. Thus, it is neither easy nor helpful to offer a guideline for how many interviews might be conducted in one day. It depends on the depth and length of each interview, in addition to language use. Reflection is important before, during, and after the interviews to enhance a meaningful understanding of an interviewee's lived experiences. Considering that a successful interview relies heavily on the interviewer's ability to probe and prompt for additional in-depth information (see Thomas, 2004), if one lacks sufficient psychological stamina in an interviews one risks losing 'access' to meaningful experiences of the interviewee (expressed in their utterances), as these may not be relayed.

Additionally, knowing all the questions by heart also assisted him in conducting interviews where it was not possible to sit down comfortably. For example, on one occasion, an interview had to be terminated after ten minutes due to the 
interviewee's baby crying and being reluctant to fall asleep. However, because the female interviewee kindly invited him to accompany her on foot to her next appointment approximately 40 minutes away, it became possible to obtain a full interview after all by continuing the conversation whilst sauntering across the Central Business District with a trolley and his digital audio recorder. In other words, the work culture of the researcher is an influential factor and an important field research practice to incorporate during methodological training in terms of gaining 'access'.

Flexibility is another issue related to the shortage of time. In the first case, the researcher observed that firms often did not want to spend too much time with a researcher. She found that a contact person would sometimes email her the day before the arranged interview requesting her to shorten the duration of the interview due to lack of time. There was nothing she could do other than express her appreciation of the situation and try her best to accommodate the changing circumstances. Furthermore, interviews and meetings can be delayed because of absence and urgent business matters. This was also experienced in the second case, where flexibility was sometimes needed when deciding if it was worth spending time pursuing a tentative interview appointment that does not seem to be materialising.

\section{Towards a Socio-cultural dimension of 'access'}

The socio-cultural dimension consists of influences from both the internal research context under study and the external. The internal research context refers to how the researcher influences the study through factors such as language and culture (see Zhang and Guttormsen, forthcoming). There may also be influences from the 
external environment (Colic-Peisker, 2004), such as how others perceive the researcher and the responses the researcher is given. This subsection focuses particularly on linguistic and cultural aspects, which cannot be separated because language constitutes a subsystem of culture (Keesing and Strathern, 1998). It can be understood as socially and historically constituted, along with other human practices (Bourdieu, 1991; 1977). The linguistic capabilities and cultural backgrounds of both researchers played an essential role when they sought the desired 'access'. These aspects have also been demonstrated to play a significant role in multicultural researchers' ability to conduct in-depth interviews (Zhang and Guttormsen, forthcoming).

It can be argued that the understanding of 'access' should not revolve solely around its physical description (i.e. as a site or firm). It should be approached as a social phenomenon, as successful 'access' depends on personality and social skills, as depicted in the 'interpersonal dimension' subsection. It is also important to reflect upon socio-cultural attributes as many of them relate to skills and/or characteristics that cannot be altered. For example, a field researcher cannot construct herself as a man if she is a woman - nor can we control how our research subjects perceive their encounters with us as the researchers (Chapman et al., 2004). This may have important implications for gaining 'access'. For example, a female sales director may feel more comfortable talking about gender issues in an MNE or about family adjustment with a female interviewer. And perhaps a male managing director may feel more comfortable talking to an interviewer with a similar business education dressed in a suit than with a young researcher wearing an anti-globalisation T-Shirt. Such evaluations are also important to make in consideration to the specific 
local/organisational cultural context. For example, the male researcher found the former example to play a diminutive role, which can be attributed to the high gender equality in Scandinavian countries (Bjerke, 1999) - the region where both researchers come from.

Similarly, researchers need to consider whether to write letters and emails in English when approaching an organisation/firm, and when to use the local dialect or their own language (in these cases, 'Scandinavian' languages). In the first case, being a native Swedish speaker, the researcher decided to conduct all contact in English when liaising with Swedish headquarters back home and when seeking access to subsidiaries in China because of the possibility of the emails being forwarded to a non-Swedish-speaking employee. Swedish employees would know from a glance at her surname that she was Swedish and might therefore instigate a two-way discussion in Swedish if they preferred - as many of the Swedish expatriates did. In the second case, the researcher found that divulging his Norwegian nationality to his research subjects helped him tremendously in terms of gaining 'access' more easily due to being defined as 'in-group' and thus having 'natural access' to events organised for Scandinavians. He also experienced a collective spirit of "we are helping out a fellow countryman" (Zhang \& Guttormsen, forthcoming).

However, 'access' should not be considered solely as an issue of locating relevant research subjects. It also relates to the sophisticated ability of researchers to access information - to comprehend, process, analyse, and interpret obtained data in the most effective and purposeful way. In this way, the "total universe of data" (Miles and 
Huberman, 1994) might be treated more accurately and authentically according to the intended transfer of meaning by the interviewee.

This was the main reason why the second author chose to investigate Scandinavian expatriates (i.e. being socio-culturally emic - an insider) in his native Norwegian language (or broken Swedish and Danish, languages which he understands and can converse in). As Spradley (1979) promulgates, "language is more than a means of communication about reality: it is a tool for constructing reality" (p. 17). Thus, he was especially well equipped to grasp nuanced meanings, contextuality, and the respondents' 'native categories' (see Buckley and Chapman, 1997), which are focal points in ethnographic research (Hammersley and Atkinson, 2007). This enhanced his social analysis by enabling him to draw upon an already in-depth understanding of the research subjects' cultural backgrounds and reference points, which signifies an important part of contextuality and intersubjectivity. The latter is paramount as human beings construct their meanings, perceptions and social reality within this contextual framework and they are constructed by it (Crotty, 2003). The abstract/immaterial nature of accessing contents relates not just to human subjects but to all types of collected data.

The socio-cultural dimension is particular a challenge in field-research conducted internationally. If a researcher is studying cultures they are not emic to, the abovementioned contextual understanding is crucial, and will inevitably impede on 'accessing' the understanding of interviewees' meaning-construction. 


\section{Discussion: moving 'access' from technicality to multidimensional continuous processes of socio-cultural field research practices}

This article highlights the need, as well as the credibility gains, that can be made by addressing 'access' in field research, as something more than a mere singledimensional technical activity (Alcadipani and Hodgson, 2009). This subsection showcases the above-mentioned encouragement in two ways: by developing a diagram showing a more comprehensive approach to 'access' as a social phenomenon, by contesting the mainstream understanding of the term 'access'; and by illuminating the continuous, relational/interpersonal nature of 'access' due to the interpretive and relational dynamics integral to gaining 'access' during field research.

First, we develop a model (Figure 1) that highlights the multidimensionality and processual facets of 'access' (beyond a mere technical activity). The boundary of the model should not be understood as fixed, in order to accommodate the relational element when it comes to achieving 'access' (see Feldman et al., 2002) as well as cultural context-specific settings. The various dimensions are highly interrelated and connected, and the significance and salience of particular dimensions depends on the context of the particular research project and location, as previously discussed. This facet also illustrates the two-way continuous process of gaining 'access'; for example, the different dimensions of 'access' are dynamics, whereby a strengthened focus on the interpersonal dimension may help to gain/extend physical access. However, the latter may also constrain 'access' in general and thus constrain the effect of a researcher's personal or socio-cultural background. Thus, the model serves as a heuristic device, which seeks to elucidate the importance of grasping 
and approaching 'access' beyond the notion of gaining physical access to a site or an interviewee (and his/her time and lived experiences).

Figure 1 Interplay and non-taxonomic nature of dimensions

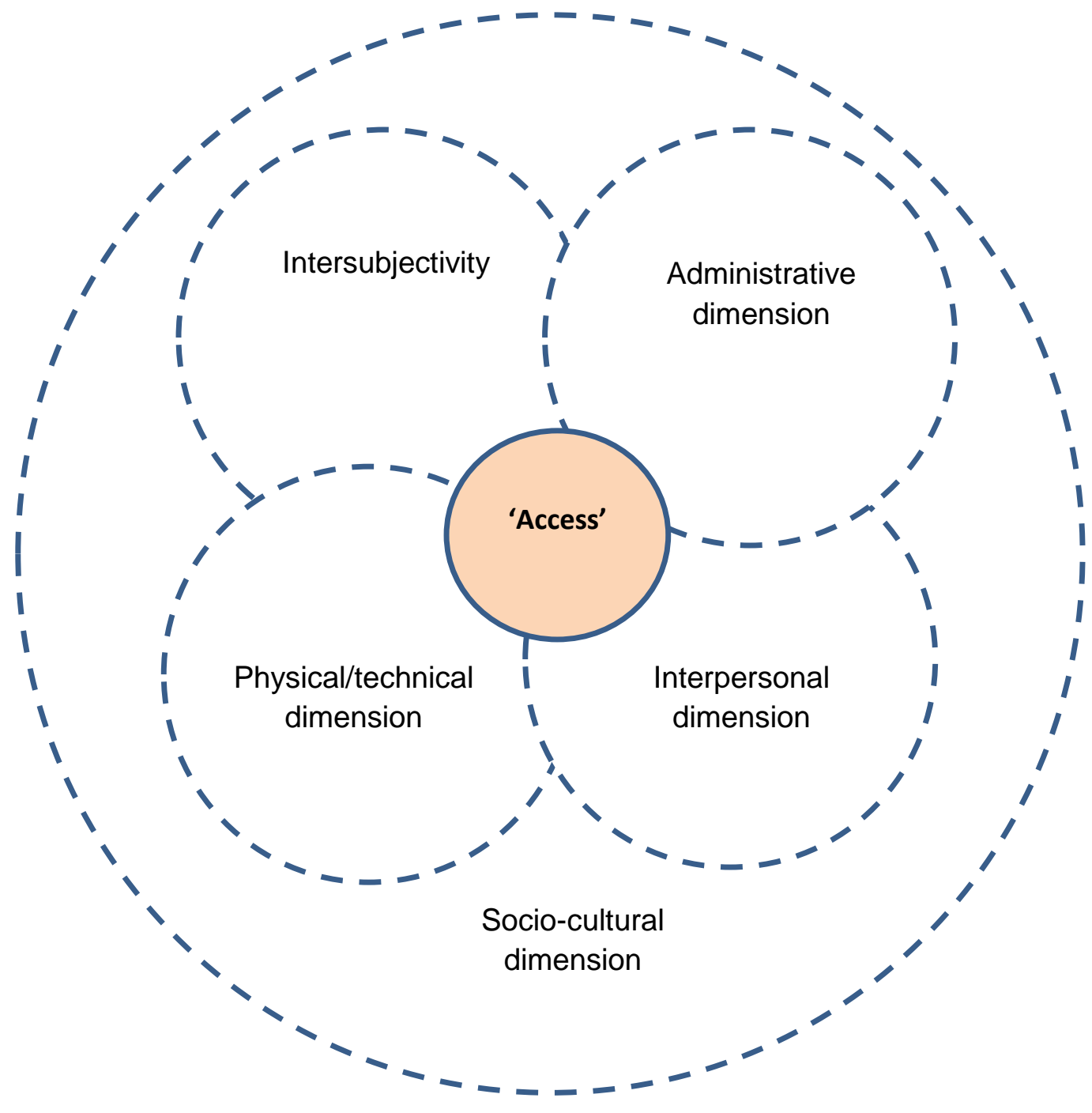

Second, we identify the importance of making sense of 'access' as a social phenomenon and a contestable term, which is neither sequential nor fixed; rather, 'access' is a phenomenon signalling a continuous process with no end-point, as shown in Figure 1, where all dimensions of 'access' function in tandem, inseparably, and non-taxonomically. For example, seeking 'access' often occurs throughout the 
duration of the field research, including when returning to the field. As Michailova et al. (2014) pinpoint, by offering a relational framework of four types of exit from the field, the nature of how we leave the geographical and conceptual space of our field research endeavours may have a direct impact on the extent to which we are welcome to re-enter the same field or reconnect with former interviewees (and firms). The relational aspects of gaining 'access' have already been accounted for, but it is also pivotal to remain focused on the fact that the above multidimensional diagram is also performing across 'levels', such as micro (individual), and macro (MNE/firm levels).

Traversing all the depicted dimensions of 'access' is the array of challenges in regard to obtaining 'access' posed by diverse international and multicultural contexts, which often are very different from the researcher's own home-environment. The identification of issues relating to dimensions and how to plan, address, and solve them - will vary across cultural, linguistic, organisational, and national boundaries. This realisation is a particular concern in the socio-cultural dimension where a lack of linguistic and cultural skills, knowledge, and savviness will potentially impede on the researcher's ability to 'access' the contents and meaning-construction relayed in research subjects' interviews and conversations. Here, risks are associated not with being able to fully 'access' intended meanings, and that the scope of analysis may be limited if the influence of context and cultural reference points are not fully grasped, which may be important for enhancing the understanding of the research problem being scrutinised.

Thus, researchers would benefit from examining and discussing the logistical and administrative aspects and, in particular, socio-cultural perspectives on obtained 
information and observations in the field at a very early stage when devising the project's research design and methodological framework. Furthermore, the enhanced understanding of the multidimensional nature of 'access' should also be evaluated with regard to its' potential impact on the researcher's ability to carry out the research (for example, methodological limitations) and the knowledge-production claims which can be made from the study undertaken.

The aforementioned levels are often interplaying with one another, and will impact on the ability of the researcher to secure 'access'. We have both experienced situations in which an interview has been accepted by the individual employee of an MNE but is later on refused at the firm-level due to political/sensitivity issues. Furthermore, the acknowledgment that 'access' is highly interpersonal and context-dependent also prompts us to consider the evident issue of the nature of 'access' beyond its status as a merely technical aspect. Although we may secure an interview, the quality and scope of data and the relayed lived experiences may be limited if we, as researchers, are unable to also access the cultural reference points/meanings of the interviewee's utterances (including translation issues) (Blenkinsopp and Palou, 2010), or if interpersonal issues impinge on how much an interviewee feels comfortable sharing in terms of his or her thoughts and sense-making of his/her own experiences (including political/sensitivity/power issues within organisations). The international setting of our field-projects further complicated issues, as knowledge of what is, for example, '(ab)normal' or 'sensitive', was sometimes unknown to us. This is a vital aspect in respect of field research practices, considering Wolcott's (1995) statement that field research interventions need to be guided by the project's overarching objectives; thus, if the purpose is to grasp the 'social realities' as 
constructed by an interviewee in his or her own context, our ability as researchers to capture this is dramatically reduced.

Thus, the different dimensions of 'access' cannot be completely distinguished from one another. Moreover, qualitative research often requires us to revisit data multiple times, and to juxtapose selected bodies of literature which are integral to the iterative, hermeneutical nature of analysis (Brewer, 2000; Hammersley and Atkinson, 2007), meaning that 'access' also becomes an issue of interpretation and social construction, as different researchers might analyse and present data in different ways due to subjectivity, intellectual biases, and personal background and position in the applicable intellectual field (see Bourdieu and Wacquant, 1992). We argue that an advanced and more holistic research practice relating to 'access', in which developments from other social science disciplines are adopted, may contribute to bridging the dominant understanding of 'access' as a technical activity in mainstream IB research, with the endeavour to take into account intersubjective, interpersonal relations, and relationality in any context-dependent situation.

\section{Conclusion}

We critically discussed the concept of 'access' as a multi-dimensional methodological issue (in interplay with physical and socio-cultural contexts), which has been under-researched in the IB literature. We have not only discussed the importance and challenges of 'access' but have also suggested a new way of exploring this issue: we have established that beyond being merely a question of gaining physical access to organisations and the time of research subjects, 'access' is a multidimensional, continuous process that needs to be unpacked in order to be 
holistically appreciated. This has been demonstrated by creating a conceptual model of 'access' (Figure 1), and thereby deliberating on the challenges faced beyond the technicalities of gaining 'access' as we experienced them in different international and multicultural settings in China. Analysing dimensions of 'access' in empirical research, where the multi-faceted nature of 'access' is evident, provides greater transparency regarding the complexity and context of the concept.

The main contribution of this article has been to help foster an academic discussion in IB research as a means of sharing experiences from the field relating to 'access' especially regarding the inclusion of a socio-culturally founded dimension within the IB discipline. The article suggests that it is insufficient to merely refer to the type of 'access' that has been secured in academic research articles and methodology textbooks. We recommend a more holistic discussion in order to fully comprehend the nature of 'access'. The provision of transparency concerning 'access' as multidimensional and as a social phenomenon should be part of any self-reflexive deliberations in order to improve the internal validity, trustworthiness, and credibility of the research (see Sinkovics et al., 2008). This encouragement also serves as a methodological contribution made by this article.

Consequently, 'access' is a highly interpersonal issue that goes beyond mere notions of physicality and technicality, and is substantially impacted by the administrative and, particularly, socio-cultural dimensions. This applies not only to locating research subjects but also to the ability to engage with information and the lived experiences imparted by research subjects, written material, and contextuality in the most effective and purposeful manner. If one secures an interview but is then 
unable to make sense of the imparted information or grasp the important nuances, the physical access to the interviewee has decreased in value in terms of the research project.

Future research might explore how socio-cultural aspects may diverge in different parts of the world, especially new emerging markets, and how 'access' is influenced by locality and different cultural environments. It is argued that this emerging line of inquiry (i.e. cultural issues in qualitative research methodologies) will be particularly profitable; for example, Zhang and Guttormsen, forthcoming) identify socio-biological traits such as skin-colour/ethnicity and having a multicultural background as factors which have a direct influence on gaining access to prospective interviewees and subsequently obtaining richer interview data. It can be argued that the dimensions of 'access' in concert warrant the development of an 'access' model. In terms of limitations, in this article we have examined our own field research experiences in China and presented them as two separate cases, hence our experiences are not necessarily transferable to every research contexts. Yet, they serve as complementary sources of accumulated learning as they highlight different perspectives on conducting qualitative field research internationally.

We have dealt with 'access' at the international level, where the challenges of 'access' are more evident compared to the national arena due to the cultural dimension. However, this article only addresses the 'access' issues that we encountered in our respective field research endeavours in China. Hence, there are many additional 'access' issues yet to be illuminated and scrutinised within various contexts. Finally, as promulgated by Humphreys (2006), we propose that 
researchers' fieldwork experiences be written up as case-studies and integrated into the curriculum as valuable sources of research training that can be delivered to postgraduate research students and management consultants (Guttormsen, 2013). 


\section{References}

Alcadipani R. and Cunliffe, A. (2014), "The Politics of Access in Organizational Ethnography", paper presented at the Qualitative Research in Management and Organization Conference, 15-17 April, Albuquerque, New Mexico, USA, available: http://business.leeds.ac.uk/qrm/qualitative-research-in-management-conference2014/ (accessed 23 May 2014).

Bate, S.P. (1997), "Whatever Happened to Organizational Anthropology? A Review of the Field of Organizational Anthropology and Anthropological Studies", Human Relations, Vol. 50 No. 9, pp 1147-1175.

Bjerke, B. (1999), Business Leadership and Culture, Edward Elgar, Cheltenham.

Blenkinsopp, J. and Pajouh, M.S. (2010), "Lost in translation? Culture, language and the role of the translator in international business", Critical Perspectives on International Business, Vol. 6 No. 1, pp. 38-52.

Bourdieu, P. (1991), Language and Symbolic Power, Polity Press, Cambridge.

Bourdieu, P. (1977), Outline of a Theory of Practice, Cambridge University Press, Cambridge.

Bourdieu, P. and Wacquant, L.J.D. (1992), An Invitation to Reflexive Sociology, Polity Press, Cambridge. 
Brewer, J.D. (2000), Ethnography, Open University Press, Buckingham.

Bryman, A. (2008), "Of methods and methodology", Qualitative Research in Organizations and Management: An International Journal, Vol. 3 No. 2, pp. 159-168.

Bryman, A. and Bell, E. (2007), Business Research Methods, 2nd edn, Oxford University Press, Oxford.

Buckley, P.J. (2004), "Foreword", in Marschan-Piekkari, R. and Welch, C. (Eds), Handbook of Qualitative Research in International Business, Edward Elgar, Cheltenham, pp.

Buckley, P.J. and Chapman, M.K. (1997), "The Use of Native Categories in Management Research", British Journal of Management, Vol. 8, No. 4, pp. 283-299.

Buckley, P.J. and Chapman, M.K. (1996a), "Economics and Social Anthropology Reconciling Differences", Human Relations, Vol. 49, No. 9, pp 1123-1150.

Buckley, P.J. and Chapman, M.K. (1996b), "Theory and Method in International Business Research", International Business Review, Vol. 5, No. 3, pp. 233-245.

Carraher, S.M. (2003), "The Father of Cross-Cultural Research: An Interview with Geert Hofstede", Journal of Applied Management and Entrepreneurship, Vol. 8, No. 2, pp 98-107. 
Casson, M. (1996), “Economics and Anthropology - Reluctant Partners", Human Relations, Vol. 49, No. 9, pp. 1151-1180.

Chapman, M.K. (1997), "Social Anthropology, Business Studies, and Cultural Issues", International Studies of Management \& Organization, Vol. 26, No. 4, pp. 329.

Chapman, M.K., Gajewska-De Mattos, H. and Antoniou, C. (2004), "The ethnographic international business researcher: Misfit or trailblazer?" in MarschanPiekkari, R. and Welch, C. (Eds), Handbook of Qualitative Research in International Business, Edward Elgar, Cheltenham, pp. 287-305.

Cole, C. (2013), "Stories from the lived and living fieldwork process", Qualitative Research in Management and Organizations, Vol. 8 No. 1, pp. 50-69.

Colic-Peisker, V. (2004), "Doing ethnography in 'one's own ethnic community": The experience of an awkward insider" in Hume, L. and Mulock, J. (Eds), Anthropologists in the Field: Cases in Participant Observation, Columbia University Press, New York, West Sussex, pp. 82-94.

Crotty, M. (2003), The Foundations of Social Research: Meaning and Perspective in the Research Process, Sage, London.

Cunliffe, A.L. (2002), "Social poetics as management inquiry: A dialogical approach", Journal of Management Inquiry, Vol. 11, No. 2, pp. 128-146. 
Demir, R. and Fjellström, D. (2012), "Translation of relational practices in an MNC subsidiary: Symmetrical, asymmetrical and substitutive strategies", Asian Business \& Management, Vol. 11 No. 4, pp. 369-393.

Donnelly, P.F., Gabriel, Y. and Özkazanç-Pan, B. (2013), "Untold stories of the field and beyond: narrating the chaos", Qualitative Research in Organizations and Management: An International Journal, Vol. 8 No. 1, pp. 4-15.

Easterby-Smith, M., Thorpe, R. and Jackson, P. (2008), Management Research, 3rd edn., Sage, London.

Edmondson, A.C. and McManus, S.E. (2007), "Fit in Management Field Research", The Academy of Management Review, Vol. 32, No. 4, pp. 1155-1178.

Feldman, M.S., Bell, J. and Berger, M.T (2003), Gaining Access A practical and theoretical guide for qualitative researchers, AltaMira Press, Walnut Creek.

Goh, S.K., Wong, K.N. and Tham, S.Y. (2013), "Trade linkages of inward and outward FDI: Evidence from Malaysia”, Economic Modelling, Vol. 35, September, pp. 224-230.

Guttormsen, D.S.A. (2015), “Looking Forward by Looking Back: a Self/Other Perspective on Intercultural Expatriate Research" in Holden, N., Michailova, S. and Tieze, S. (Eds), Routledge Companion to Cross-Cultural Management, Routledge, Oxford/New York, pp. 344-354. 
Guttormsen, D.S.A. (2013), “(Self) Reflexivity as Method(ology): Advancing International Business Research", in Academy of International Business 2013 proceedings of the 55th Annual Meeting in Istanbul, Turkey, p. 247.

Guttormsen, D.S.A. (2010), “Unlocking Complexity with Simplicity: A Social Constructionist take on the 'Ethnographic Interview in Multilingual and Intercultural 'Multi-site' field research”, in European Conference on Research Methodology for Business and Management Studies 2010 proceedings, pp. 157-165.

Guttormsen, D.S.A. (2009), "Institutions of Scandinavian expatriatism in Hong Kong: A dynamic perspective on interaction and adjustment", working paper (no. 91), David C. Lam Institute for East-West Studies (LEWI), Hong Kong Baptist University, pp. 3-50.

Hammersley, M., and Atkinson, P. (2007), Ethnography, Routledge, London.

Holmes, P. (2015), "Intercultural encounters as socially constructed experiences; Which concepts? Which pedagogies?", in Holden, N., Michailova, S. and Tieze, S. (Eds), Routledge Companion to Cross-Cultural Management, Routledge, Oxford/New York, pp. 237-247.

Humphreys, M. (2006), "Teaching qualitative research methods: I'm beginning to see the light", Qualitative Research in Organizations and Management: An International Journal, Vol. 1 No. 3, pp. 173-188. 
Jackall, R. (1988), Moral Mazes: The World of Corporate Managers, Oxford: University Press.

Keesing R.M. and Strathern A.J. (1998), Cultural Anthropology: A Contemporary Perspective, 3rd edn., Thomson, Belmont.

Lauring, J. (2007), "Language and ethnicity in international management", Corporate Communications: An International Journal, Vol. 12 No. 3, pp. 255-266.

Lauring, J. and Guttormsen, D.S.A. (2010), "Challenges of ethnicity in organizational interaction: The role of language use", in Crennan, J.K. (Ed.), Ethnicity: Cultural roles, Spiritual Practices, and Social Challenges, Nova Science Publishers, New York.

Locke, K. (2011a), "Looking for what we have a case of", Qualitative Research in Organizations and Management: An International Journal, Vol. 6, No. 1.

Locke, K. (2011b), "Field Research Practice in Management and Organization Studies: Reclaiming its Tradition of Discovery", The Academy of Management Annals, Vol. 5 No. 1, pp. 613-652.

Locke, K. and Ramakrishna Velamuri, S. (2009), "The Design of Member Review: Showing What to Organization Members and Why", Organizational Research Methods, Vol. 12, No. 3, pp. 488-509. 
Macdonald, S. and Hellgren, B. (2004), "The Interview in International Business Research: Problems We Would Rather Not Talk About", in Marschan-Piekkari, R. and Welch, C. (Eds), Handbook of Qualitative Research in International Business, Edward Elgar, Cheltenham, pp. 264-284.

Magolda, P.M. (2000), “Accessing, waiting, plunging in, wondering, and writing: Retrospective sense-making of fieldwork", Field Methods, Vol. 12 No. 3, pp. 209234.

Marschan-Piekkari, R. and Welch, C. (Eds) (2004), Handbook of Qualitative Research in International Business, Edward Elgar, Cheltenham.

Michailova, S., Piekkari, R., Plakoyiannaki, E., Ritvala, T., Mihailova, I. and Salmi, A. (2014), "Breaking the Silence about Exiting Fieldwork: A Relational Approach and its Implications for Theorizing", Academy of Management Review, Vol. 39 No. 2, pp. 138-161.

Mikkelsen, E.N. (2013), “A researcher's tale: how doing conflict research shapes research about conflict", Qualitative Research in Organizations and Management: An International Journal, Vol. 8 No. 1, pp. 33-49.

Miles, M.B. and Huberman, A.M. (1994), Qualitative Data Analysis: An Expanded Sourcebook, 2nd edn., Sage, London. 
Olesen, V. (1994), "Feminism and models of qualitative research", in Denzin, N.K. and Lincoln, Y.S. (Eds), Handbook of qualitative research, Sage, Thousand Oaks, CA, pp. 158-174.

Orr, K. and Bennett, M. (2009), "Reflexivity in the co-production of academicpractitioner research", Qualitative Research in Organizations and Management: An International Journal, Vol. 4 No. 1, pp. 85-102.

Peticca-Harris, A., deGama, N. and Elias, S. (2014), "Greed, grit, and qualitative research: Stories of securing samples", paper presented at the Qualitative Research in Management and Organization Conference, 15-17 April, Albuquerque, New Mexico, USA, available: http://business.leeds.ac.uk/qrm/qualitative-research-inmanagement-conference-2014/ (accessed 23 May 2014).

Primecz, H., Romani, L. and Sackmann, S. (2011), Cross-cultural Management in practice: culture and negotiated meanings, Edward Elgar, Cheltenham.

Rabinow, P. (1977), Reflections on fieldwork in Morocco, University of California Press, Berkeley.

Radcliffe, L.S. (2013), "Qualitative diaries: uncovering the complexities of work-life decision-making", Qualitative Research in Organizations and Management: An International Journal, Vol. 8 No. 2, pp. 163-180. 
Sanday, P.R. (1979), "The Ethnographic Paradigm(s)”, Administrative Science Quarterly, Vol. 24, No. 4, pp. 527-538.

Sinkovics, R., Penz, E. and Ghauri, P. (2008), "Enhancing the Trustworthiness of Qualitative Research in International Business", Management International Review, Vol. 48, No. 6, pp. 689-714.

Spradley, J.S. (1979), The Ethnographic Interview, Wadsworth Thomson Learning, Belmont.

Taylor, S. and Land C. (2014), "Organizational anonymity and the negotiation of research access", Qualitative Research in Organizations and Management: An International Journal, Vol. 9 No. 2, pp. 98-109.

Thomas, A.B. 2004, Research skills: For management studies, Routledge, London.

Tomkins, L. and Eatough, V. (2010), "Towards an integrative reflexivity in organisational research", Qualitative Research in Organizations and Management: An International Journal, Vol. 5 No. 2, pp. 162-181.

Van Maanen, J. (1988), Tales of the field: On writing ethnography, University of Chicago Press, Chicago.

Whyte, W.F. (1997), Creative problem solving in the field: Reflections on a career, AltaMira, Walnut Creek. 
Wolcott, H.F. (1995), The art of fieldwork, AltaMira, Walnut Creek.

Zhang, L.E. and Guttormsen, D.S.A. (forthcoming), “'Multiculturality' as a Key Methodological Challenge during In-depth Interviewing: Knowledge Transfer across Cultural Boundaries", Cross Cultural Management: an International Journal. 